\title{
PERAMALAN ESTIMATED ULTIMATE RECOVERY MENGGUNAKAN METODE WATER OIL RATIO PADA SUMUR $X$
}

\author{
Dorothea Dyah Puspita $^{1)}$, Onnie Ridaliani ${ }^{2)}$, Listiana Satiawati ${ }^{3)}$ \\ ${ }^{1)}$ Mahasiswa Jurusan Teknik Perminyakan - Universitas Trisakti \\ 2) Dosen Pembimbing I Jurusan Teknik Perminyakan - Universitas Trisakti \\ ${ }^{3)}$ Dosen Pembimbing II Jurusan Teknik Perminyakan - Universitas Trisakti \\ E-mail: dorotheapuspita@gmail.com
}

\begin{abstract}
In the management of oil and gas fields, production forecasting is needed to find out the steps to be taken in the future. Therefore, in this study the prediction of the well potential was carried out using the water oil ratio method. The prediction of potential wells referred to in this study is to predict the estimated ultimate recovery (EUR) or cumulative value of oil production in the future. Well $X$ has a well problem in the form of excess water production and after being analyzed using Chan's Diagnostic Plot, the result is that the well has water channeling. The type of water channeling is in well $X$ experiencing near wellbore channeling. After knowing the type of water problem, a prediction of the potential of the well (cumulative maximum production) is carried out, both wells have water channeling and wells that are normal or not experiencing problems. Prediction of well potential in the form of cumulative maximum production value or Estimated Ultimate Recovery (EUR) is obtained by the water oil ratio method. This method is using five plots including water cut, oil fraction, cumulative WOR, cumulative watercut, and finally 1 / fw which is compared with each with maximum cumulative production. Then after it was discovered that the EUR value of each well experienced both water and normal problems, it was found to lose the cumulative prediction of the production of each well. The loss of EUR well $X$ is 551,267 STB.
\end{abstract}

Keywords: Water Oil Ratio, Chan's Diagnostic Plot, Water Channeling, Estimated Ultimate Recovery

\begin{abstract}
Abstrak
Pada pengelolaan lapangan migas, diperlukan peramalan produksi untuk mengetahui langkah-langkah yang akan diambil dikemudian hari. Oleh karena itu, pada penelitian ini dilakukan prediksi potensi sumur dengan metode water oil ratio. Prediksi potensi sumur yang dimaksud pada penelitian kali ini yaitu untuk memprediksi nilai estimated ultimate recovery (EUR) atau kumulatif produksi minyak dimasa mendatang. Sumur X memiliki permasalahan sumur berupa produksi air yang berlebih dan setelah dianalisa menggunakan Chan's Diagnostic Plot, didapatkan hasil bahwa sumur mengalami water channeling. Jenis dari water channeling tersebut yaitu pada sumur $\mathrm{X}$ mengalami near wellbore channeling. Setelah mengetahui jenis permasalahan air tersebut, dilakukan prediksi potensi sumur (kumulatif produksi maksimum) baik sumur mengalami water channeling maupun sumur yang normal atau tidak mengalami permasalahan. Prediksi potensi sumur yang berupa nilai kumulatif produksi maksimum atau Estimated Ultimate Recovery (EUR) didapatkan dengan metode water oil ratio. Metode ini yaitu menggunakan lima plot-plot diantaranya water cut, fraksi minyak, kumulatif WOR, kumulatif watercut, dan terakhir yaitu $1 / \mathrm{fw}$ yang dibandingkan masing-masing dengan kumulatif produksi maksimum. Lalu setelah diketahui nilai EUR dari masing-masing sumur baik itu mengalami permasalahan air maupun normal, didapatkan kehilangan prediksi kumulatif produksi masing-masing sumur. Kehilangan EUR sumur X yaitu 551,267 STB.
\end{abstract}

Kata kunci: Water Oil Ratio, Chan's Diagnostic Plot, Water Channeling, Estimated Ultimate Recovery 


\section{Pendahuluan}

Lapangan X terletak di Jawa Timur dan ditemukan pada tahun 2001 dan mulai diproduksikan pada Juli 2004 sampai saat ini dan jenis batuan dari lapangan ini adalah karbonat. Pada pengelolaan lapangan migas, kegiatan produksi dilakukan seoptimal mungkin sehingga didapatkan hasil yang maksimal. Oleh karena itu diperlukan peramalan produksi untuk mengetahui langkah-langkah yang akan diambil dikemudian hari. Pada penelitian ini akan dilakukan prediksi potensi sumur pada sumur $\mathrm{X}$ menggunakan metode Water Oil Ratio. Setelah diproduksikan, sumur X ini mengalami produksi air yang berlebih. Hal ini dapat dilihat dari grafik production performance dari masing-masing sumur. Jumlah air dan minyak yang ikut terproduksi tersebut dapat dianalisia dan di prediksi nilai Estimated Ultimate Recovery atau kumulatif produksi maksimum dari masing-masing sumur sehingga dapat mengetahui langkah selanjutnya dalam pengembangan sumur $X$.

\section{Studi Pustaka}

Pada sumur minyak yang bertenaga dorong air sering kali mengalami problem produksi air. Sebenarnya problem yang ditimbulkan karena peningkatan produksi air tidak hanya water coning tetapi dapat juga channeling, yaitu saluran air yang terbentuk dalam suatu zona minyak. Untuk itu sangat penting dilakukan diagnose mengidentifikasi masalah produksi air agar dapat dilakukan penanggulangan problem dengan metode yang tepat. ${ }^{1}$ Chan, K. S. (1995) memberikan suatu metode yang dapat dipakai untuk mendiagnosa secara tepat dan mengevaluasi problem yang timbul menggunakan plot yang dihasilkan dari data sejarah produksi suatu sumur yang dianalisa. Plot tersebut diantaranya: (1) Plot sejarah produksi untuk seluruh periode produksi minyak, air, dan gas (2) Plot antara WOR dan WOR' (3) Plot produksi minyak kumulatif dengan efisiensi recovery (4) Laju penurunan minyak dan gas. Plot-plot ini menunjukan suatu gambaran perilaku produksi masa lalu, saat ini dan sisa potensi produksi sumur tersebut. Plot loglog dari WOR vs waktu memberikan hasil yang paling efektif dalam mengidentifikasi tren produksi dan mekanisme permasalahan. Dengan kata lain bahwa turunan dari WOR vs waktu dapat digunakan untuk membedakan apakah kelebihan masalah produksi air dalam suatu sumur dikarenakan oleh water coning atau water channeling. Metode ini dapat menjadi salah satu cara yang sangat efektif untuk pemilihan pekerjaan perbaikan sumur akibat produksi air yang berlebihan sehingga dapat meningkatkan tingkan kesuksesasn saat dilakukan pekerjaan perbaikan sumur.

Problem dekat sumur sering terjadi secara tiba-tiba selama normal displacement dan produksi Near Wellbore Channeling. Dengan menggunakan WOR' (turunan dari WOR), coning dan channeling dapat dilihat dan dibedakan. Lebih jauh lagi, perubahan slope dari WOR dan WOR' dan nilai dari WOR' menjadi indikator yang baik untuk membedakan normal displacement dan kelakuan sumur saat produksi. Beberapa keuntungan dari teknik ini yaitu (1) Menggunakan data sejarah produksi sumur yang tersedia. (2) Dapat digunakan dengan untuk melihat banyak sekali sumur. (3) Hasilnya dapat dijadikan sebagai dasar saat melakukan survey mekanisme produksi, membendingkan mekanisme tersebut pada sumur-sumur yang berdekatan, sumur produksi yang baik vs sumur produksi yang bermasalah, berdasarkan pola area atau pola sumurnya. (4) Dengan plot antara WOR vs produksi minyak kumulatif, teknik ini dapat menjadi sebuah metode yang sangat efektif untuk memilih kandidat sumur untuk perbaikan. (5) Dengan menggunakan teknik diagnostic ini yang merupakan salah satu metode dalam mendiagnosa water problem, maka akan didapatkan keuntungan produksi dan pemahaman yang komprehensif (Chan, 1995).

Umumnya sangat sulit untuk menganalisa dan memperkirakan produksi minyak pada reservoir bertenaga dorong air. Metode ini menyajikan pengembangan dan hubungan antara water oil ratio (WOR), fungsi watercut ( $f_{\ldots}$ ), fraksi minyak $\left(f_{-}\right), h_{i}^{\prime \prime}(\tau) R$.

(kumulatif water oil ratio), $f_{., y}$ (kumulatif watercut), dan $\stackrel{1}{-}$. Model baru ini disertakan

reservoir dan sifat fluida untuk kedua fase (minyak dan air) dan didasarkan pada asumsi kondisi aliran pseudosteady-state. Oleh karena itu metode ini akan dapat mewakili dalam memperkirakan volume produksi maksimum minyak karena menggunakan data-data produksi air, produksi minyak, dan WOR dalam perhitungannya yang masing-masing di- 
plot dengan kumulatif produksi minyak sehingga didapatkan nilai kumulatif produksi maksimum berdasarkan teknik ekstrapolasi (Bondar, 2002).

$$
\begin{aligned}
& W O R=\frac{q_{w}}{q_{D}} \\
& W O R^{\prime}=\frac{W O R_{2}-W O R_{1}}{\mathrm{t}_{2}=t_{1}} \\
& f_{W}=\frac{q_{w}}{q_{w}+q_{o}} \\
& f_{0}=\frac{q_{o}}{q_{w}+q_{o}} \\
& W O R_{C}=\frac{W p}{N p} \\
& f_{W c}=\frac{W p}{W p+N p} \\
& \frac{1}{f_{w}}=\frac{q_{0}+q_{w}}{q_{w}}
\end{aligned}
$$

Teknik ini menggunakan fungsi plotting sebagai berikut:

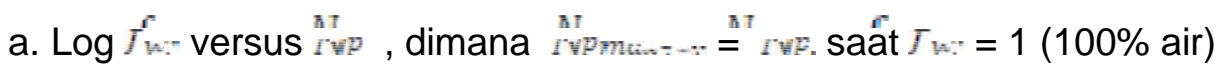

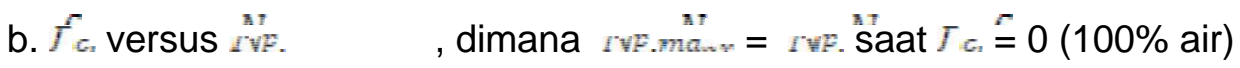

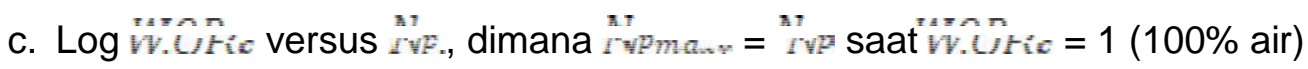

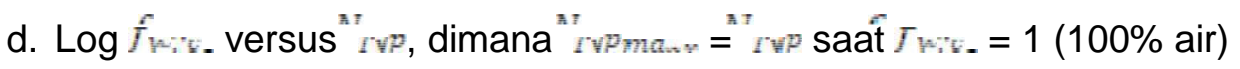

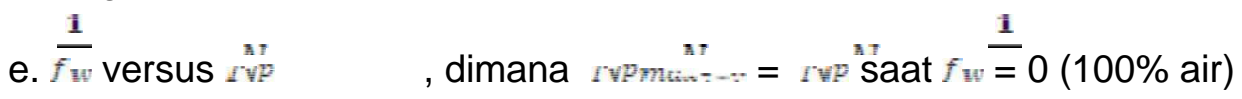

\section{Matodologi Penelitian}

Dalam menghitung Estimated Ultimate Recovery menggunakan metode Water Oil Ratio dibutuhkan data sejarah produksi dari sumur tersebut. Setelah dianalisa data produksi dari sumur, didapatkan kesimpulan bahwa pada sumur $X$ ini memiliki permasalahan air yang berlebih. Oleh karena itu, untuk mengetahui jenis permasalahan tersebut, dianalisa menggunakan Chan's Diagnostic Plot.

Tujuan dari penelitian ini yaitu untuk mengetahui prediksi potensi sumur (kumulatif produksi maksimum) minyak menggunakan metode Water Oil Ratio. Pada penelitian ini, kumulatif produksi maksimum dapat diprediksi untuk dua kondisi yaitu pada saat kondisi sumur belum mengalami permasalahan air (keadaan normal) dan pada saat kondisi sumur sedang mengalami permasalahan air. Hal ini diperlukan untuk mengetahui kehilangan kumulatif produksi maksimum suatu sumur sehingga dapat dilakukan tindakan selanjutnya dalam pengembangan sumur itu sendiri. Bisa diasumsikan bahwa kehilangan kumulatif produksi yang besar bisa menyebabkan ketidakekonomisan suatu sumur, sehingga bisa dilakukan langkah selanjutnya agar sumur tersebut bisa ekonomis kembali. Oleh karena itu, hasil analisa dan prediksi dari penelitian ini dapat menjadi salah satu masukan untuk kandidat sumur perbaikan karena sudah mengetahui forecast dari kumulatif produksi dan mengetahui penyebab dari kehilangan kumulatif produksi tersebut (permasalahan air).

Analisa prediksi potensi sumur menggunakan metode Water Oil Rátio. Metode ini harus memenuhi beberapa kondisi diantaranyac(1) Harus memenuhi plot-plot kondisi aliran pseudosteade-state. Plot-plot tersebut harus dipenuhi untuk menunjukkan satu nilai Estimated Ultimate Recovery atau kumulatif produksi maksimum untuk mendapatkan estimasi kosisten dari nilai kumulatif produksi maksimum atau EUR tersebut. Oleh karena terdapat lima plot yang berbeda, maka diperlukan nilai error terhadap rata-rata dari perolehan EUR sehingga, nilai prediksi kumulatif produksi sumur diperoleh dari persen error terkecil dari plot-plot dalam metode Water Oil Ratio tersebut. Pada metode ini, digunakan teknik ekstraplolasi yaitu teknik peramalan dengan memproyeksikan kecenderungan masa lalu ke masa depan untuk meminimalisir ketidaktepatan. Seteah diketahui nilai prediksi Estimated Ultimate Recovery dari masing-masing sumur dalam 
kondisi normal maupun kondisi permasalahan air tersebut, dihitung nilai kehilangan kumulatif produksi agar dapat menjadi salah satu masukan untuk kandidat sumur perbaikan dalam pengembangan sumur $\mathrm{X}$.

\section{Hasil dan Pembahasan}

Berdasarkan data produksi, didapatkan hasil bahwa air terproduksi secara berlebihan. Analisa permasalahan air pada sumur tersebut dapat dilihat dari analisa Chan's Diagnostic Plot, yaitu plot antara WOR dan WOR' terhadap waktu. Sumur X didapatkan hasil analisa berupa Near Wellbore Channeling. Jenis channeling ini biasanya dikarenakan terdapat masuknya air didekat wellbore. Pada lapangan PHN, hasil dari Chan's Diagnostic Plot membuktikan bahwa hanya terjadi water channeling karena semen yang tidak meerkat dengan baik yang diakibatkan oleh struktur geologi yang berupa batuan karbonat sehingga aliran yang terbentuk bukan dari matriks-matriks batuan, tetapi aliran air yang menembus zona minyak tersebut berasal dari rekahan yang terbentuk karena batuan karbonat itu sendiri.

Metode water oil ratio ini harus memenuhi persyaratan yaitu memplot antara fraksi air (fw) dengan kumulatif produksi (Np), fraksi minyak dengan Np, kumulatif WOC dengan $\mathrm{Np}$, kumulatif fraksi air dengan $\mathrm{Np}$, dan 1/fw dengan $\mathrm{Np}$ dan cara untuk mengetahui nilai prediksi potensi sumur tersebut (kumulatif produksi maksimum) menggunakan teknik ekstrapolasi. Semua plot-plot tersebut dilakukan untuk mendapatkan estimasi yang konsisten dari nilai EUR.

Setelah itu, untuk mengetahui nilai EUR, diplot kembali antara watercut dengan kumulatif produksi dengan jarak waktu antara awal produksi hingga sebelum terjadi channeling, kira-kira pada hari ke-2255. Hal ini menyebabkan dapat diketahui nilai kumulatif produksi maksimum pada saat sumur keadaan normal (belum mengalami channeling) menggunakan teknik ekstrapolasi. Hasil prediksi Estimated Ultimate Recovery yaitu sebesar 9963,817 STB. Setelah itu, dilakukan kembali plot antara watercut vs kumulatif produksi pada waktu sumur mengalami near wellbore water channeling yaitu pada hari ke-2256 sampai akhir masa produksi. Setelah didapatkan garis yang mewakili titik tersebut, dilakukan teknik ekstrapolasi dan didapatkan nilai prediksi kumulatif produksi sebesar 9268,533 STB. Teknik yang diekstrapolasi pada kurva ini yaitu menuju ke angka 1. Hal ini menunjukkan bahwa nilai prediksi kumulatif produksi maksimum terletak ketika sumur mengalami watercut $100 \%$.

Plot antara watercut versus kumulatif produksi maupun fraksi oil (fo) versus kumulatif produksi memperlihatkan garis lurus yang kuat. Garis lurus pada semilog menunjukkan bahwa pola aliran tersebut pseudosteady-state. Model aliran pseudosteadystate mempunyai asumsi bahwa pada waktu tertentu tekanan pada matriks batuan disetiap titik menurun jika di produksikan dengan laju alir konstan. Kemudian aliran dari matriks ke rekahan sebanding dengan perbedaan tekanan antara tekanan matriks dan tekanan di dekat rekahan. Pada kemiringan tersebut, formasi berkelakuan seperti reservoir homogen dengan kontribusi aliran seluruhnya hanya berasal dari rekahan. Plot selanjutnya yaitu WORc, kumulatif watercut, dan 1/fw masing-masing terhadap kumulatif produksi dengan cara yang sama seperti plot antara watercut versus kumulatif produksi dan fraksi minyak versus kumulatif produksi. Teknik ekstrapolasi yang digunakan pada plot kumulatif WOR versus kumulatif produksi maksimum dan kumulatif watercut ini yaitu mendekati 1 karena nilai kumulatif produksi maksimum terletak ketika $100 \%$ air atau tidak adanya minyak yang ikut terproduksi. Sedangkan untuk 1/fw versus kumulatif produksi maksmium teknik ekstrapolasi yaitu mendekati 0 karena nilai kumulatif produksi maksimum terjadi disaat $100 \%$ air.

Nilai error diperlukan dalam penelitian ini untuk mengetahui tingkat ketidakpastian dari interpretasi yang telah dilakukan. Oleh karena itu, nilai error ini didapatkan berdasarkan perbandingan antara rata-rata dari nilai kumulatif produksi maksimum dari keadaan sumur (normal atau channeling) terhadap masing-masing metode yang ada. Dari nilai error tersebut, persentase dari masing-masing keadaan sumur dan diambil nilai error yang paling kecil sebagai suatu acuan untuk mendapatkan nilai kumulatif produksi 
maksimum pada sumur $\mathrm{X}$. Nilai kumulatif produksi maksimum terbesar dilihat dari error yang terkecil. Pada penelitian ini, tingkat error yang diperbolehkan yaitu kurang lebih $5 \%$.

Sumur X memiliki nilai kumulatif produksi maksimum dari sumur normal (yang tidak mengalami permasalahan air) sebesar 9819,8 STB dan nilai kumulatif produksi maksimum dari sumur channeling yaitu 9268,533 STB. Hal ini menyebabkan perkiraan nilai kumulatif produksi yang hilang akibat dari channeling sebesar 551,267 STB dan sumur X teridentifikasi Near Wellbore Water Channeling. Berdasarkan plot-plot antara watercut $\left(f_{w}\right)$ dengan kumulatif produksi, fraksi minyak $\left(f_{-}\right)$dengan kumulatif produksi, kumulatif WOR $\left(\left[\eta_{*}^{*} l_{2}, R_{2}\right)\right.$ dengan kumulatif produksi, kumulatif watercut $\left(f_{\mathrm{s}}\right)$ dengan kumulatif produksi, serta $\frac{i}{f_{w}}$ dengan kumulatif produksi, didapatkan ringkasan hasil ekstrapolasi untuk sumur X pada tabel 1.

Tabel 1. Analisa EUR Sumur X

\begin{tabular}{|c|l|c|c|}
\hline Keadaan Sumur & \multicolumn{1}{|c|}{ Metode } & Np max (STB) & Error \\
\hline \multirow{4}{*}{ Normal } & $f_{W}$ versus $N_{p}$ & 9963,817 & $1,598 \%$ \\
\cline { 2 - 4 } & $f_{o}$ versus $N_{p}$ & 9671,667 & $1,381 \%$ \\
\cline { 2 - 4 } & $W O R_{c}$ versus $N_{p}$ & 9852,782 & $0,466 \%$ \\
\cline { 2 - 4 } & $f_{W c}$ versus $N_{p}$ & 9819,800 & $0,129 \%$ \\
\cline { 2 - 4 } & $\frac{1}{f_{w}}$ versus $N_{p}$ & 9727,500 & $0,812 \%$ \\
\hline \multirow{4}{*}{ Channeling } & $f_{W}$ versus $N_{p}$ & 9268,533 & $0,311 \%$ \\
\cline { 2 - 5 } & $f_{o}$ versus $N_{p}$ & 9331,000 & $0,361 \%$ \\
\cline { 2 - 5 } & $W 0 R_{c}$ versus $N_{p}$ & 9357,878 & $0,650 \%$ \\
\cline { 2 - 5 } & $f_{w c}$ versus $N_{p}$ & 9357,963 & $0,651 \%$ \\
\cline { 2 - 5 } & $\frac{1}{2}$ versus $N_{p}$ & 9172,029 & $1,349 \%$ \\
\hline
\end{tabular}

\section{Kesimpulan}

1) Pada sumur $X$ terjadi permasalahan air yaitu berupa water channeling.

2) Berdasarkan Chan's Diagnostic Plot, sumur X mengalami permasalahan Near Wellbore Channeling.

3) Sumur X memiliki prediksi Estimated Ultimate Recovery pada keadaan normal sebesar 9819,800 STB dan setelah mengalami Near Wellbore Water Channeling diprediksikan memiliki kumulatif produksi maksimum sebesar 9268,533 STB oleh karena itu mengalami kehilangan kumulatif produksi sebesar 551,267 STB.

\section{Daftar Pustaka}

Bondar, V. (2002), Analysis and Interpretation of Water Oil Ratio Performance, Journal Society of Petroleum Engineers.

Chan, K. S. (1995): Water Control Diagnostic Plot, Journal Society of Petroleum Engineers.

Rukmana, D., Kristanto, D., and Aji, D. C. (2012). Teknik Reservoir: Teori dan Aplikasi, Pohon Cahaya, Yogyakarta. 